\title{
Optimal Power Flow with Reactive Power Compensation for Cost And Loss Minimization On Nigerian Power Grid System
}

\author{
Ganiyu Adedayo Ajenikoko*, Olakunle, Elijah Olabode \\ Department of Electronic \& Electrical Engineering, Ladoke Akintola University of Technology, P.M.B. 4000, \\ Ogbomoso, Nigeria. \\ e-mail: ajeedollar@gmail.com
}

\begin{abstract}
One of the concerns of power system planners is the problem of optimum cost of generation as well as loss minimization on the grid system. This issue can be addressed in a number of ways; one of such ways is the use of reactive power support (shunt capacitor compensation). This paper used the method of shunt capacitor placement for cost and transmission loss minimization on Nigerian power grid system which is a 24-bus, 330kV network interconnecting four thermal generating stations (Sapele, Delta, Afam and Egbin) and three hydro stations to various load points. Simulation in MATLAB was performed on the Nigerian $330 \mathrm{kV}$ transmission grid system. The technique employed was based on the optimal power flow formulations using Newton-Raphson iterative method for the load flow analysis of the grid system. The results show that when shunt capacitor was employed as the inequality constraints on the power system, there is a reduction in the total cost of generation accompanied with reduction in the total system losses with a significant improvement in the system voltage profile.
\end{abstract}

Keywords: Power Flow, Cost minimization, Loss minimization, Shunt capacitor compensation, NewtonRaphson iteration method.

\section{Introduction}

One of the major concerns of power system planner/ utility companies is the problem of optimum cost of generation as well as loss minimization on the grid system while supplying power to the public in a robust and reliable manner [1]. Optimal power flow aims to optimize a specific objective function, subject to the network power flow equations and system as well as equipment operating limits. The optimal condition is attained by adjusting the available controls to minimize an objective function subject to specified operating and security requirements. The concept of optimal power flow (OPF) was firstly introduced in early 1960s by Carpentier [2, 3] and ever since, a number of dynamic researchers have solved OPF problems with different methods ranging from Convectional to Artificial intelligence methods. The earliest technique for solving considerable large power systems was based on the Gauss-Seidel method [4], though this approach has its own inherent disadvantages such as poor convergence rate, large number of iteration and large computation time.

In a bid to solve the problem of convergence, Newton-Raphson iterative method was formulated. However, the fundamental problem associated with this approach is bus admittance matrix for multinomial dimensions [5].Fast decouple Newton-Raphson method is also a tool for solving optimal power flow problems. A comprehensive literature survey of OPF covers classical local nonlinear techniques- linear programming method, Newton-Raphson's method, quadratic programming method, nonlinear programing method, interior point as well as the artificial intelligent method [6] - Artificial Neural Network (ANN), Fuzzy Logic Method (FL), Genetic Algorithm (GA) Method, Evolutionary Programming (EP), Ant Colony Optimization (ACO). Particle Swarm Optimization (PSO) algorithms are global optimization techniques, they are less likely to get trapped in local solutions if these exist. As knowledge search exercise advances, a mean of arriving at global optimum solutions evolved which is metaheuristic in nature [7]. They overcome the problem of convergence to local solutions which is evidently the core drawback of conventional OPF techniques.

In this paper, the researchers studied the effect of shunt capacitor setting. which is a reactive compensation placed at specified generating stations to minimize the cost of 
generation, reduce transmission loss as well as its effects on the voltage profile on Nigerian power grid system. This is essentially a 24-bus, 330kV network interconnecting four thermal generating stations (Sapele, Delta, Afam and Egbin) and three hydro stations to various load points as shown in Figure 1.

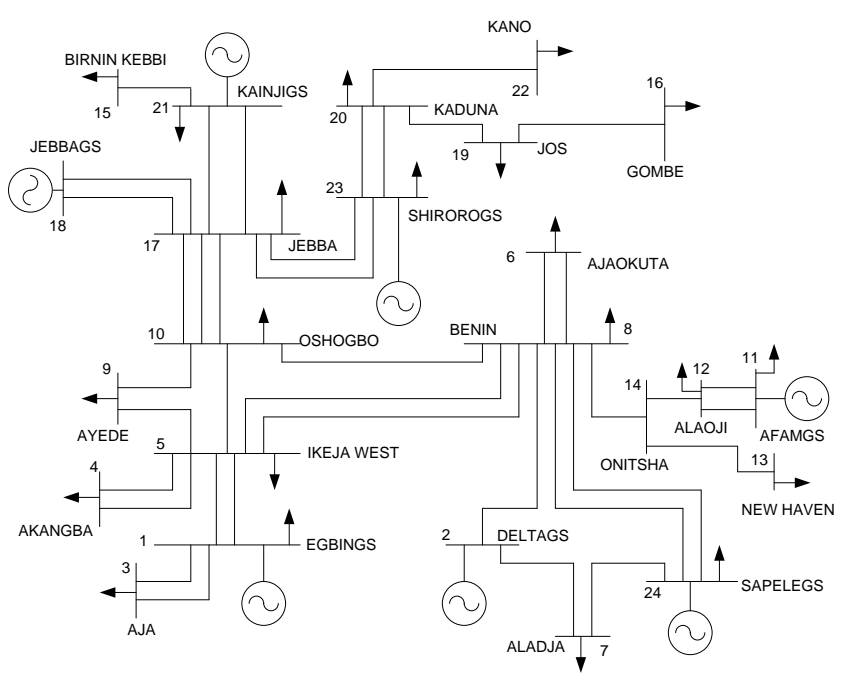

Figure 1. One line diagram of Nigerian $330 \mathrm{kV}$

\subsection{The Load Flow Problem}

\subsubsection{Classification of Bus}

Generally, buses in power system are of three types: Slack Bus (reference bus), Load Bus (P-Q Bus) and Voltage Controlled Bus (P-V Bus). In slack bus, both the voltage magnitude and the phase angle are specified, the real and reactive powers are not specified. I, in P-Q Bus, the real and reactive power are specified while the voltage magnitudes and the phase angles are not specified and in P-V Bus, the voltage magnitude and the injected real power are specified.

\subsubsection{Power Flow Model Based Newton-Raphson Iteration Method}

Load flow analysis based on Newton-Raphson method is an iterative method which approximates a set of non-linear simultaneous equations to a set of simultaneous linear equations using Taylor's series expansion while limiting the term to first order approximation. The real and imaginary part for ith bus voltages will be represented by a set of non-linear equations using Rectangular Coordinates defined by equation (1).

$$
\begin{aligned}
& P_{i}-j Q_{i}=V_{i}^{*} I_{i}=V_{i}^{*} \sum_{i=1}^{n} Y_{i k} V_{k} \\
& i f V_{i}, V_{k} \text { and } Y_{p q} \text { are represented by (2), (3) and (4) as follows; } \\
& V_{i}=e_{i}+j f_{i} \\
& V_{k}=e_{k}+j f_{k} \\
& Y_{i k}=G_{i k}-j B_{i k}
\end{aligned}
$$

where $e_{i}$ and $f_{i}$,represent real and imaginary part of $V_{i}, e_{k}$ and $f_{k}$ represent real and imaginary part $V_{\mathrm{k}}$ while $\mathrm{G}_{\mathrm{ik}}$ and $\mathrm{B}_{\mathrm{ik}}$ are the conductance and susceptance respectively. Inserting these quantities into the equation (1), then separate $P_{i}$ and $Q_{i}$ for ith bus, then the following equations are got; 


$$
\begin{aligned}
& P_{i}=e_{i}\left(e_{i} G_{i i}+f_{i} B_{i i}\right)+f_{i}\left(f_{i} B_{i i}-e_{i} B_{i i}\right)+\sum_{k=1, k \neq i}^{n}\left[e_{i}\left(e_{k} G_{i k}+f_{k} B_{i k}\right)+f_{i}\left(f_{k} G_{i k}-e_{k} B_{i k}\right)\right] \\
& Q_{i}=f_{i}\left(e_{i} G_{i i}+f_{i} B_{i i}\right)-e_{i}\left(f_{i} B_{i i}-e_{i} B_{i i}\right)-j \sum_{k=1, k \neq i}^{n}\left[f_{i}\left(e_{k} G_{i k}+f_{k} B_{i k}\right)-e_{i}\left(f_{k} G_{i k}-e_{k} B_{i k}\right)\right]
\end{aligned}
$$

At each bus, both $P_{i}$ and $Q_{i}$ which are non-linear algebraic equations will be calculated except at the slack; altogether there are $2 \mathrm{n}-1$ non-linear algebraic equations to be solved. The fundamental idea on which Newton-Raphson method is based has to do with its ability to transform a set of the nonlinear equations to linear equations by the iteration. For simplicity, the above equations (5) and (6) can be written in simple compact matrix form as defined below.

$$
\left[\begin{array}{l}
\Delta \mathrm{P} \\
\Delta \mathrm{Q}
\end{array}\right]=\left[\begin{array}{ll}
\mathrm{J}_{1} & \mathrm{~J}_{2} \\
\mathrm{~J}_{3} & \mathrm{~J}_{4}
\end{array}\right]\left[\begin{array}{c}
\Delta \delta \\
\Delta \mathrm{v}
\end{array}\right]
$$

where, $\Delta \mathrm{P}$ and $\Delta \mathrm{Q}$ are bus active and reactive power mismatches, $\Delta$ Vand $\Delta \delta$ represent bus voltage angle and magnitude vectors in an incremental form while $J_{1}$ to $J_{4}$ is the Jacobian matrix of partial derivatives of real and reactive power with respect to the voltage magnitude and angles.

\subsection{Reactive Power Compensation}

With the background understanding of the fact that nothing can be done to active power flow in power system, the reactive power flow can be manipulated based on the pressing needs either by injecting or removing it from the system[8]. Reactive power compensation played benefiting roles in power system such as improving steady-state and dynamic stability, improving voltage profiles of the system and reduction of network loss if correctly placed[9]. Injecting reactive power correctly into the system reduces transmission losses, improves voltage profile of the system and as well decreases line loading [10]-[15]. Reactive power can be injected at the specified buses via shunt capacitor to reduce transmission loss, increase system voltage profile and reduce cost of generation.

\section{Materials and Method}

\subsection{Formulaton of Optimal Power Flow (Opf)}

The load flow problem and OPF problem are inseparable in the sense that every feasible point of OPF must satisfy the load flow equations. OPF seeks to minimize the total fuel cost while meeting the operational constraints of the power system- equality and inequality constraints- The desired minimum cost of generation can be achieved by scheduling unit outputs of committed power generators at generating station. The cost of the power system is fundamentally attributed to the cost of generating power at each generator and the generating cost for a generator exhibits a linear function with the real power output and is independent of reactive power output of each generator.

\subsection{The Objective Function}

The objective of OPF is to find the overall costs of all generators in a power system. The cost model for power generation is given as

where;

$$
\mathrm{C}_{\mathrm{P}_{\mathrm{Gi}}}=\mathrm{a}_{\mathrm{i}} \mathrm{P}_{\mathrm{Gi}}^{2}+\mathrm{b}_{\mathrm{i}} \mathrm{P}_{\mathrm{Gi}}+\mathrm{c}_{\mathrm{i}}
$$

$\mathrm{C}_{\mathrm{P}_{\mathrm{Gi}}}=$ the fuel cost of $\mathrm{i}^{\text {th }}$ generator (Naira/ hours),

$\mathrm{P}_{\mathrm{Gi}}=$ the power generated at generator $\mathrm{i}^{\text {th }}$, and

$a_{i}, b_{i}$ and $c_{i}=$ fuel cost coefficient $i^{\text {th }}$ generator.

For a power system with $\mathrm{N}$ number of generators, the objective function is the sum of the cost model for each generator given by ;

where

$$
\mathrm{F}_{\mathrm{P}_{\mathrm{Gi}}}=\sum_{\mathrm{i}=1}^{\mathrm{N}}\left(\mathrm{a}_{\mathrm{i}} \mathrm{P}_{\mathrm{Gi}}^{2}+\mathrm{b}_{\mathrm{i}} \mathrm{P}_{\mathrm{Gi}}+\mathrm{c}_{\mathrm{i}}\right)
$$

$\mathrm{F}_{\mathrm{P}_{\mathrm{Gi}}}=$ Total fuel cost (Naira/hour) 


\subsection{System Constraint}

The two basic constraints on power system are equality constraint (power balanced constraint) and the inequality constraint

Equality Constraint: cost of generation is linearly dependent on the real power and independent of reactive power, the sum of real power of all the generating units must be equal to the total real power demand on the system in addition to power transmission loss as given by

$$
\sum_{\mathrm{i}=1}^{\mathrm{n}} \mathrm{P}_{\mathrm{gi}}=\mathrm{P}_{\mathrm{d}}+\mathrm{P}_{\mathrm{L}}
$$

where;

$\mathrm{P}_{\mathrm{Gi}}=$ real power generated at generator $\mathrm{i}^{\text {th }}$

$\mathrm{P}_{\mathrm{d}}=$ Total real power demand and,

$\mathrm{P}_{\mathrm{L}}=$ Power transmission loss

Transmission loss is explicitly a function of unit generation. It is viewed as a loss of revenue by the utility and a true economic dispatch provision has to be made for reduction of transmission losses. Basically, penalty factor method and the B coefficients method are two known methods of evaluating transmission losses. Power utility engineers use B-coefficients method. In this work, B-coefficient method was used to determine the transmission losses $\left(\mathrm{B}_{\mathrm{ij}}\right)$ and power transmission losses defined by

$$
\mathrm{P}_{1}=\sum_{\mathrm{i}=1}^{\mathrm{n}} \sum_{\mathrm{j}=1}^{\mathrm{n}} \mathrm{B}_{\mathrm{ij}} \mathrm{P}_{\mathrm{i}} \mathrm{P}_{\mathrm{j}}
$$

Inequality Constraint: this refers to limit defined on physical devices-generators, tap changing transformers and phase shifting transformers etc- on power system to ensure system security. The limit on the generator output is defined by

$$
\mathrm{P}_{\mathrm{Gi}}^{\min } \leq \mathrm{P}_{\mathrm{GI}} \leq \mathrm{P}_{\mathrm{Gi}}^{\max }
$$

Security range of bus voltage is given by:

$$
V_{i}^{\min } \leq V_{i} \leq V_{i}^{\max }
$$

where $\mathrm{P}^{\min }$ and $\mathrm{P}^{\max }$ stand for lower and upper limits for active power generation, $\mathrm{V}^{\mathrm{min}}$ and $\mathrm{V}^{\text {max }}$ are minimal acceptable voltage levels at each bus.

\section{Simulation}

All simulations were carried out using MATLAB (2012a) version on 24-bus systems, 330kV Nigerian grid system and it was run on a portable computer with an Intel Core2 Duo $(1.8 \mathrm{GHz})$ processor, 2GB RAM memory and MS Windows 7 as an operating system. For both cases that load flow with and without shunt compensation, the accuracy of $1.000 \mathrm{e}^{-003}$ was specified in the power flow program. The maximum power mismatch of $3.49553 \mathrm{e}^{-07}$ was obtained from the power flow solutions and convergence is reached after the fifth iterations.

\section{Discussion}

Observations also show that when the shunt compensation was employed as the inequality constraint on the power system, there is a reduction in the total cost of generation which accompanied reduction in total system losses along sides with a significant improvement in the system voltage profile.

The total injected MVAr in the system is 99Mvar, out of which 24 MVAr was injected at Egbin thermal station while 25MVAr each was injected at Delta,Afam and Sapele thermal stations respectively. These injected MVAr reduces the cost of generation from $1488724.17 \$ / \mathrm{h}$ to $1488679.71 \$ / \mathrm{h}$. The percentage reduction in the cost of generation is calculated to be2.98e$5 \%$. The reduction seems insignificant in terms of percentage hourly reduction; however when the reduction is expressed in term of annual reduction it will definitely become significant. 
The total system losses at steady state condition was found to be $82.5982 \mathrm{MW}$. With shunt compensation the total system losses reduces drastically to $82.2826 \mathrm{MW}$. The percentage reduction in total system losses is $3.82 \mathrm{e}-3 \mathrm{MW}$. The introduction of shunt compensation brought about improvement on the system voltage profile as evidently seen on the buses $6,12,13$ and 14 respectively. On bus 6 , the voltage magnitude with capacitor setting was $1.0544 \mathrm{~V}$ while without the capacitor setting, the voltage magnitude is $1.0543 \mathrm{~V}$, thus the improvement was $0.0001 \mathrm{~V}$. On bus 12 , the voltage magnitude with capacitor setting was $1.0338 \mathrm{~V}$ while without the capacitor setting the voltage magnitude was $1.0329 \mathrm{~V}$, thus the improvement was $0.0009 \mathrm{~V}$. On bus 13, the voltage magnitude with capacitor setting was $0.9292 \mathrm{~V}$ while without the capacitor setting the voltage magnitude was $0.9287 \mathrm{~V}$, thus the improvement was $0.0005 \mathrm{~V}$. Lastly, on bus 14 , the voltage magnitude with capacitor setting was $0.9717 \mathrm{~V}$ while without the capacitor setting the voltage magnitude was $0.9712 \mathrm{~V}$, thus the improvement was $0.0005 \mathrm{~V}$.

\subsection{Graphical Illustrations}

\subsubsection{Case 1: Power Flow solution by Newton Raphson's Method without shunt Compensation}

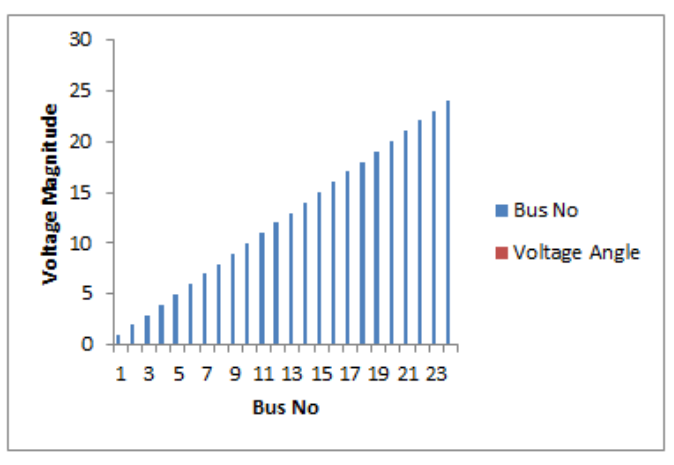

Figure 1. Voltage Magnitude versus Bus No

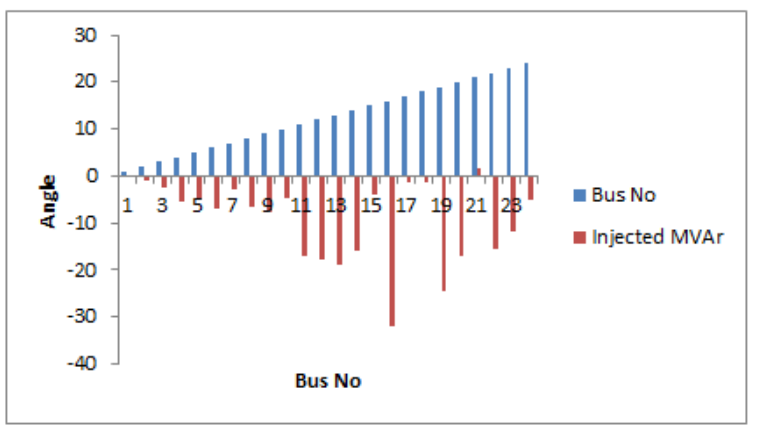

Figure 2. Angle versus Bus No 


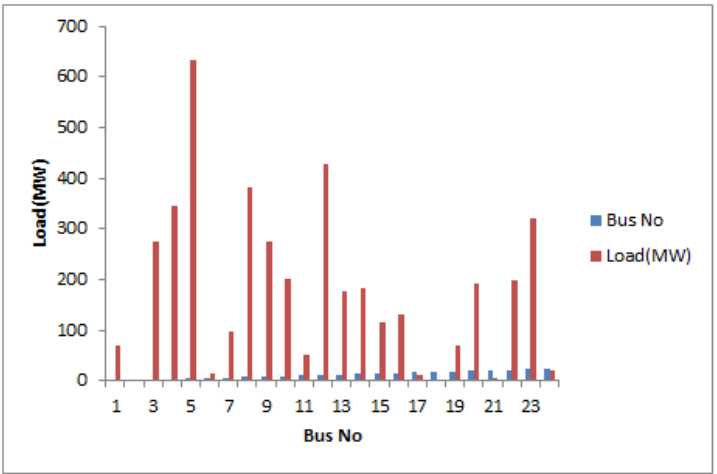

Figure 3. Load(MW) versus Bus No

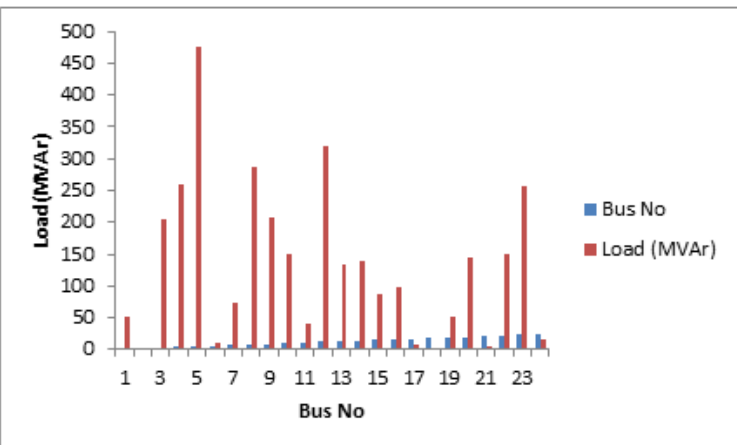

Figure 4. Load (MVAr) versus Bus No

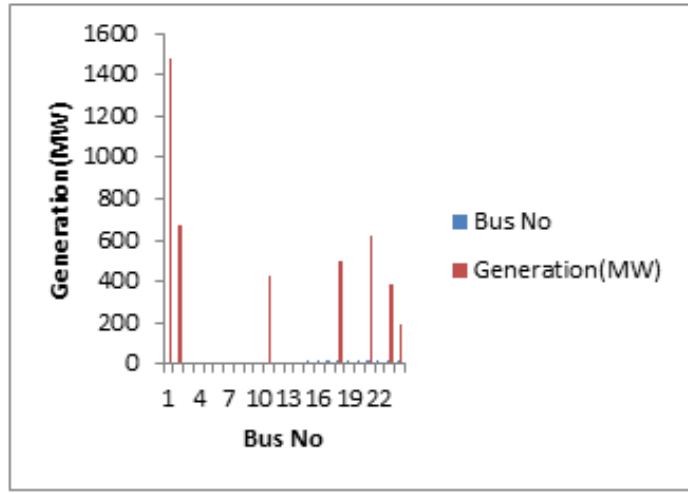

Figure 5. Generation (MW) versus Bus No

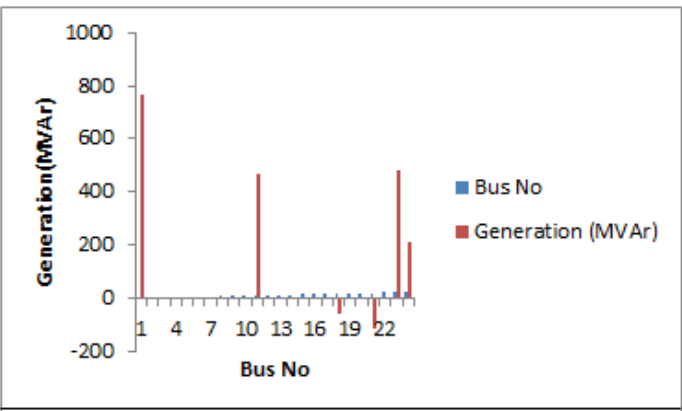

Figure 6. Generation MVAr) versus Bus No 


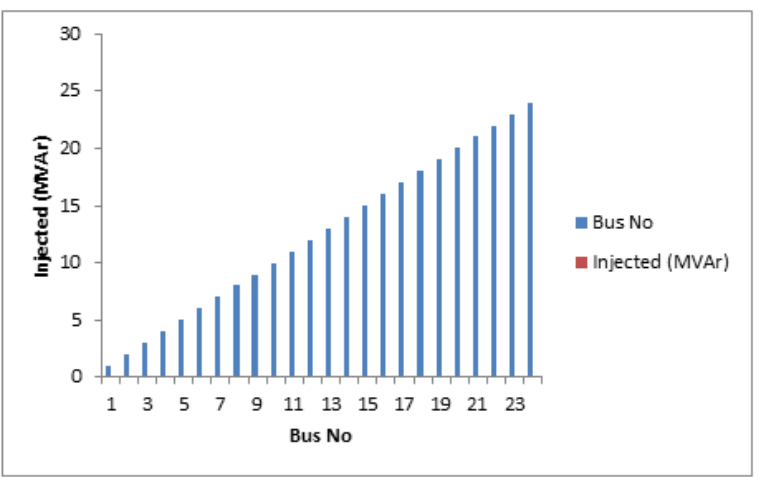

Figure 7. Injected MVAr versus BusNo

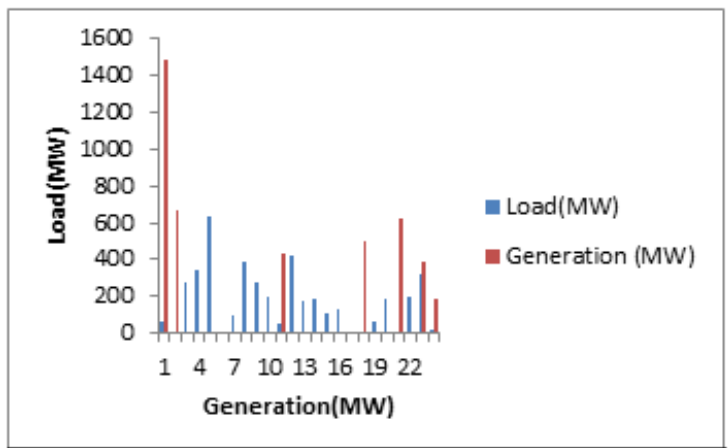

Figure 8. Load(MW) versus Generation (MVAr)

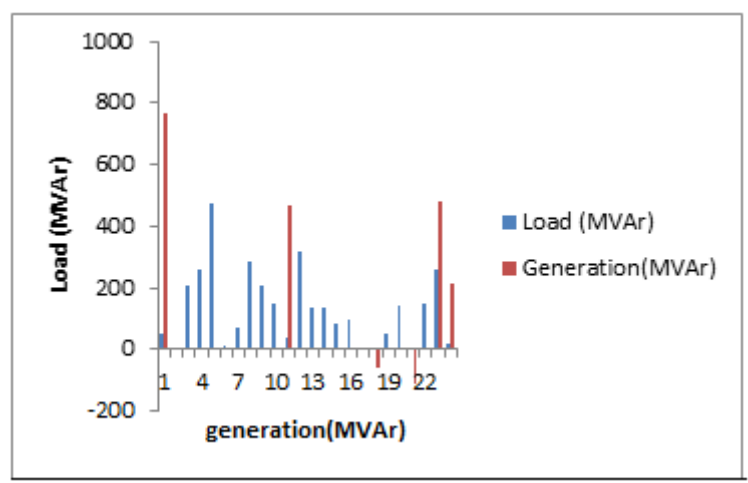

Figure 9. Load (MVAr) versus Generation (MVAr)

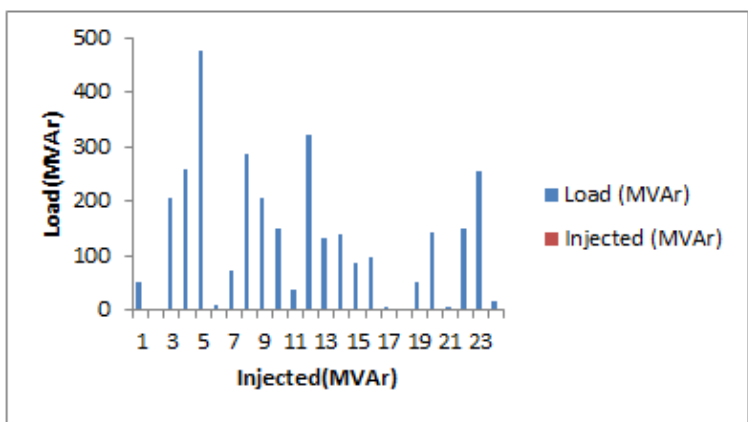

Figure 10. Load (MVAr) versus Injected (MVAr) 


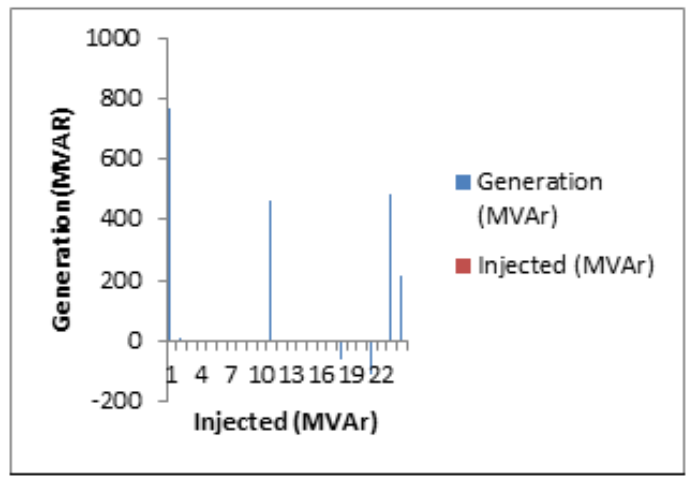

Figure 11. Generation (MVAr) versus Injected (MVAr)

CASE II: Power Flow solution by Newton Raphson's Method with shunt Compensation

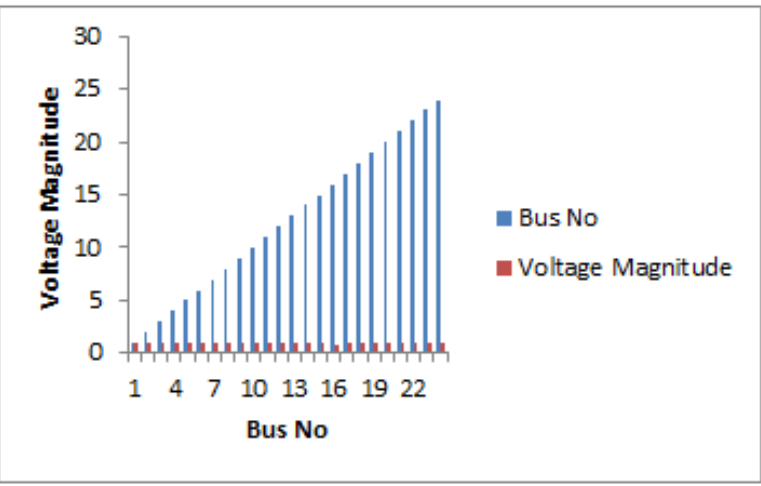

Figure 12. Voltage Magnitude versus Bus No

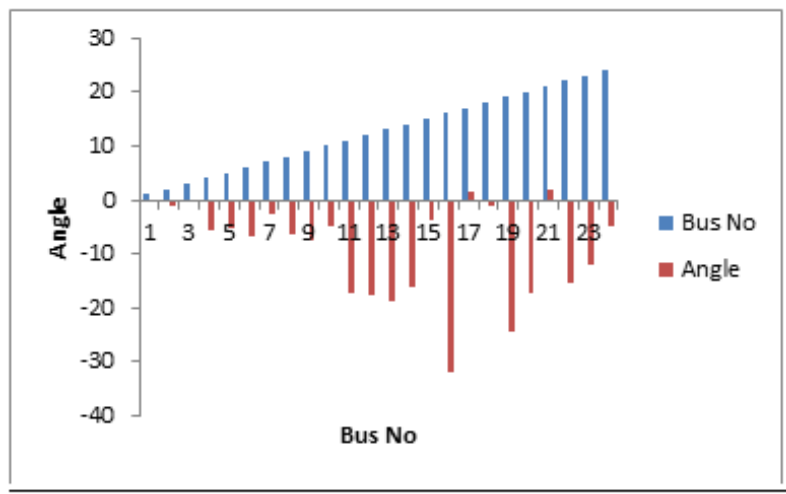

Figure 13. Angle versus Bus No 


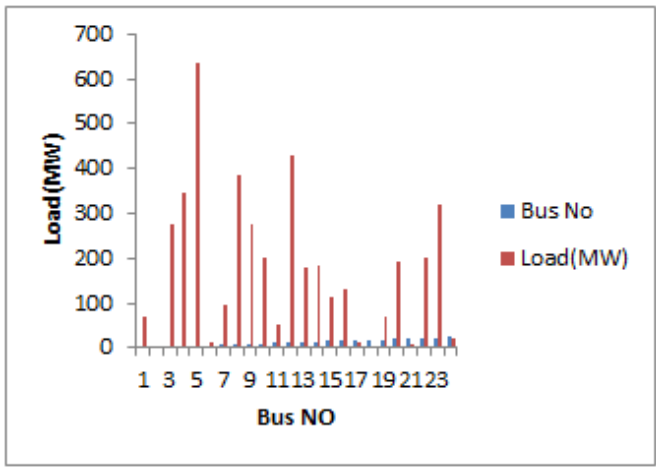

Figure 14. Load (MW) versus Bus No

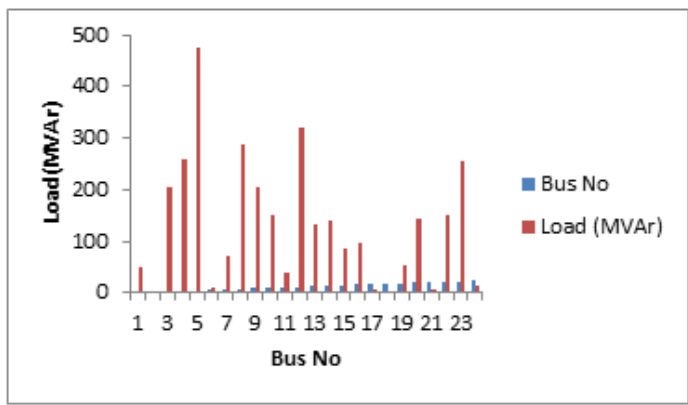

Figure 15. Load (MVAr) versus Bus No

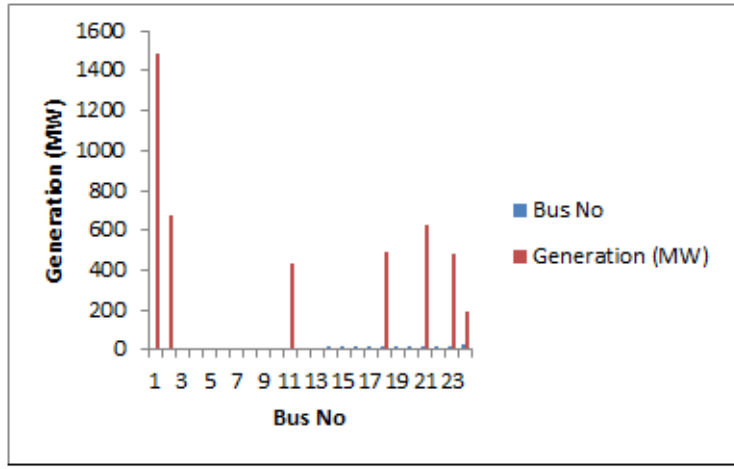

Figure 16. Generation (MW) versus Bus No

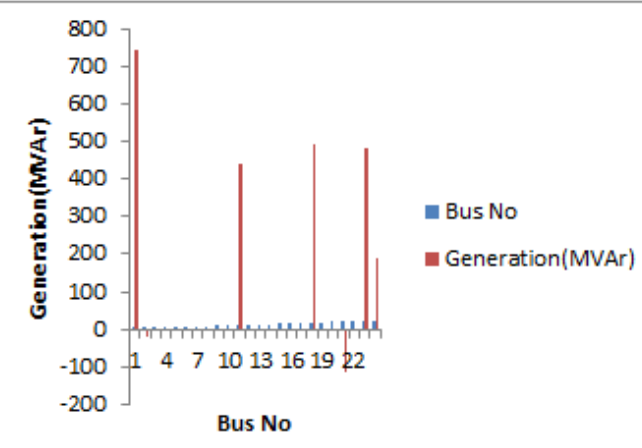

Figure 17. Generation (MVAr) versus Bus No 


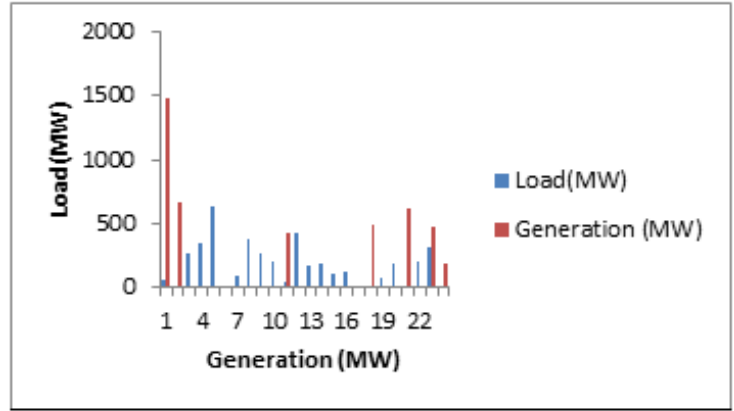

Figure 18. Load (MW) versus Generation (MW)

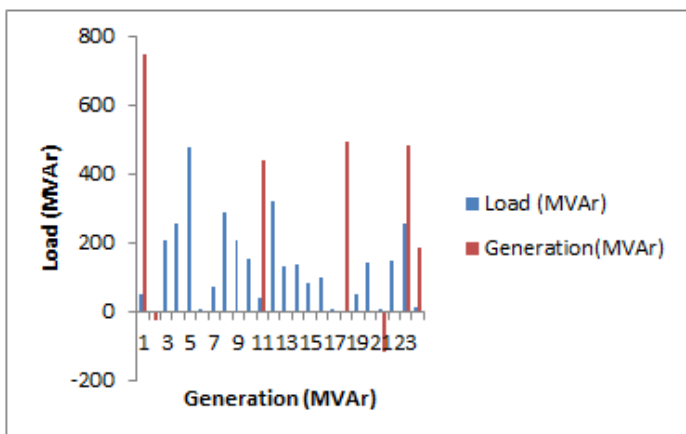

Figure 19. Load (MVAr) versus Generation MVAr)

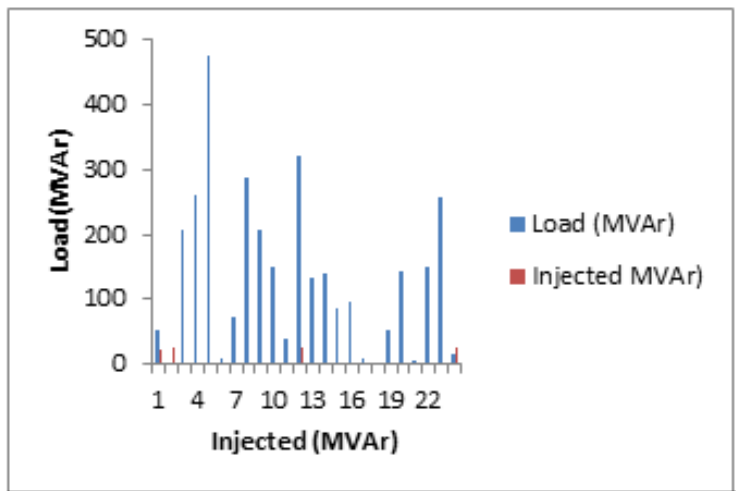

Figure 20. Load MVAr) versus Injected (MVAr)

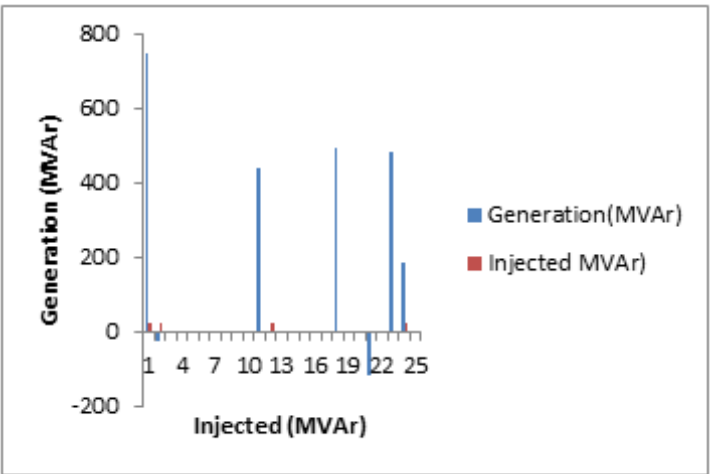

Figure 21. Generation (MVAr) versus Injected (MVAr) 


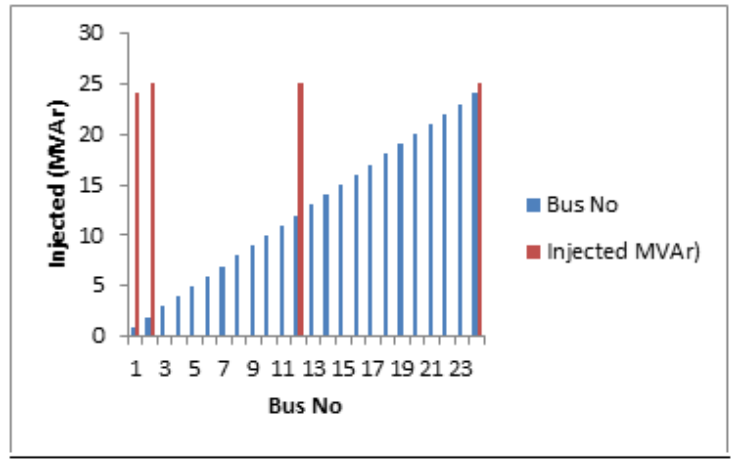

Figure 22. Injected (MVAr) versus Bus No

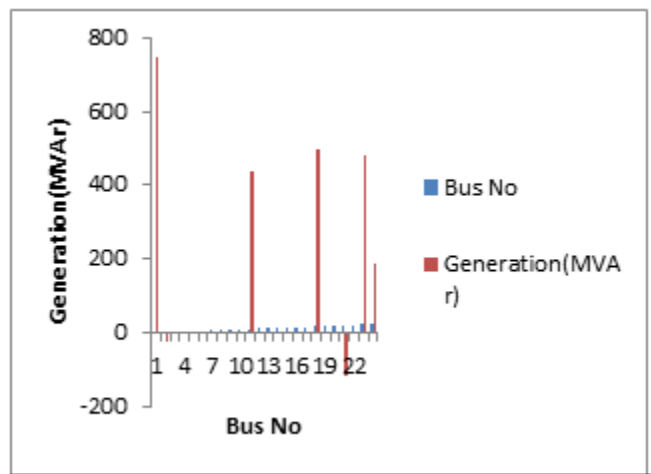

Figure 23. Generation (MVAr) versus Bus No

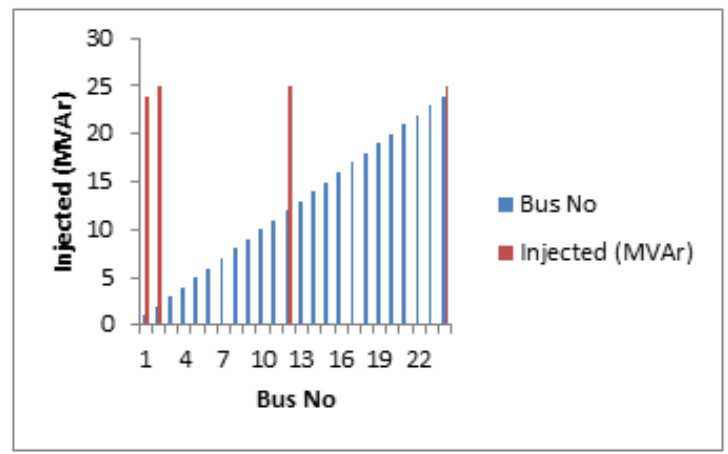

Figure 24. Injected (MVAr) versus Bus No

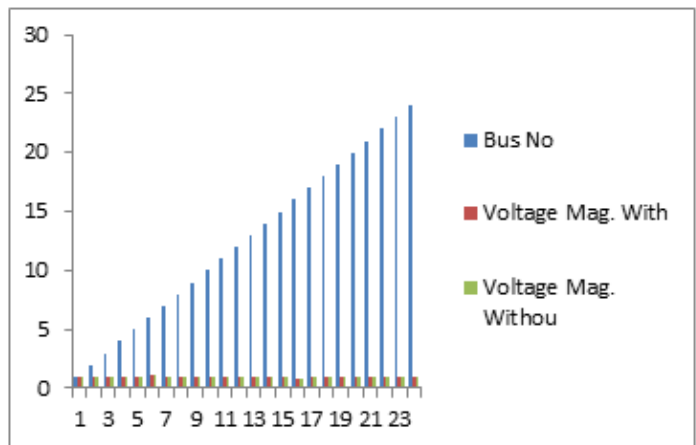

Figure 25. Voltage Mag.(with and without capacitor setting) versus Bus No 


\section{Conclusion}

A shunt compensation via optimal capacitor placement for the active power losses reduction, minimization of cost of generation and improvement in system voltage profile using optimal power flow program implemented in MATLAB environment has been presented. The method was implemented on Nigerian power grid system which is a 24-bus, 330kV network interconnecting four thermal generating stations (Sapele, Delta, Afam and Egbin) and three hydro stations to various load points. The study reveals that the injected MVAr brings about reduction in the total cost of generation, the total system losses and a significant improvement in the system voltage profile.

\section{References}

[1] Singh J, Wadhwani S. Economic Load Dispatch Problem Using Firefly Algorithm. International Journal of Scientific \& Engineering Research. 2013; 4(6): 2155-2160.

[2] Carpienter J. Contribution El'étude do Dispatching Economique. Bulletin Society Française des Electriciens. 1962; 3: 431-447.

[3] Weber JD. Implementation of a newton-based optimal power flow into a power system simulation environment. 1997. Ph.D. dissertation. University of Illinois.

[4] Alvarado FL, Thomas RJ. A brief history of the power flow. http://spectrum.ieee.org/energy/thesmarter-grid/visualizing-the-electricgrid/4/egridsb1. University of Wisconsin, Madison. 2003.

[5] Peschon J, Piercy DS, Tinney WF, Tveit OJ, Cuénod M. Optimum Control of Reactive Power Flow. IEEE Transactions on Power Apparatus and Systems. 1968; 87(1): 40-48.

[6] Zhifeng Q, Geert D, Ronnie B. A literature survey of optimal power flow problems in electricity market context. IEEE Power systems conference and Exposition.

[7] Al Rashidi MR, El-Hawary ME. Applications of computational intelligence technique for solving the revived optimal power flow problem. Electric Power System Research. 2009.

[8] Dommel HW, Tinney WF. Optimal Power Flow solutions. IEEE Transactions on Power Apparatus and Systems. 1968; 87: 1866-1876.

[9] Momoh JA, El-Hawary ME, Ramababu Adapa. A Review Of Selected Optimal Power Flow Literature to. Part 1: Nonlinear and Quadratic Programming Approaches. IEEE Trans. on Power Systems. 1991.

[10] Otar Gavasheli. Optimal Placement of Reactive Power Supports for Loss Minimization: The Case of A Georgian Regional Power Grid. Thesis for the Degree of Master of Science, Division of Electric Power Engineering, Department of Energy and Environment. Chalmers University Of Technology Göteborg, Sweden. 2007.

[11] Timothy JE, Miller, John Wiley. Reactive Power Control in Electric Systems. 2nd Edition. New York. 1982.

[12] Abdel-Moamen MA, Padhy NP. Power Flow Control and Transmission Loss Minimization Model with TCSC for Practical Power Networks. IEEE Power Engineering Society General Meeting. 2003; 2: 880-884.

[13] Mamandur KRC, Chenoweth RD. Optimal Control of Reactive Power Flow for Improvement in Voltage Profiles and for Real Power Loss Minimization. IEEE Transactions on Power Apparatus and Systems. 1981; 100(7): 1509-1515.

[14] lyer SR, Ramachandran K, Hariharan S. Optiaml Reactive Power Allocation for Improved System Performance. IEEE Transactions on Power Apparatus and Systems. 1984; 103(6).

[15] Wollenberg BF. Transmission system reactive power compensation. IEEE Power Engineering Society Winter Meeting. 2002; 1: $507-508$. 